\title{
Experimental Evidence for the Optimal Design of a High-Performing Cloth Mask
}

\author{
Shovon Bhattacharjee,* Prateek Bahl, Charitha de Silva, Con Doolan, Abrar Ahmad Chughtai, \\ David Heslop, and Chandini Raina MacIntyre
}

Cite This: ACS Biomater. Sci. Eng. 2021, 7, 2791-2802

Read Online

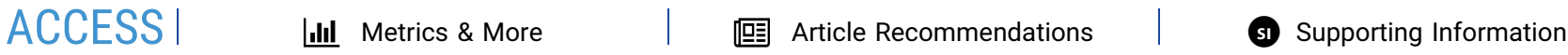

ABSTRACT: Cloth masks can be an alternative to medical masks during pandemics. Recent studies have examined the performance of fabrics under various conditions; however, the performance against violent respiratory events such as human sneezes is yet to be explored. Accordingly, we present a comprehensive experimental study using sneezes by a healthy adult and a tailored imagebased flow measurement diagnostic system evaluating all dimensions of protection of commonly available fabrics and their layered combinations: the respiratory droplet blocking efficiency, water resistance, and breathing resistance. Our results reveal that a well-designed cloth mask can outperform a three-layered surgical mask for such violent respiratory events. Specifically, increasing the

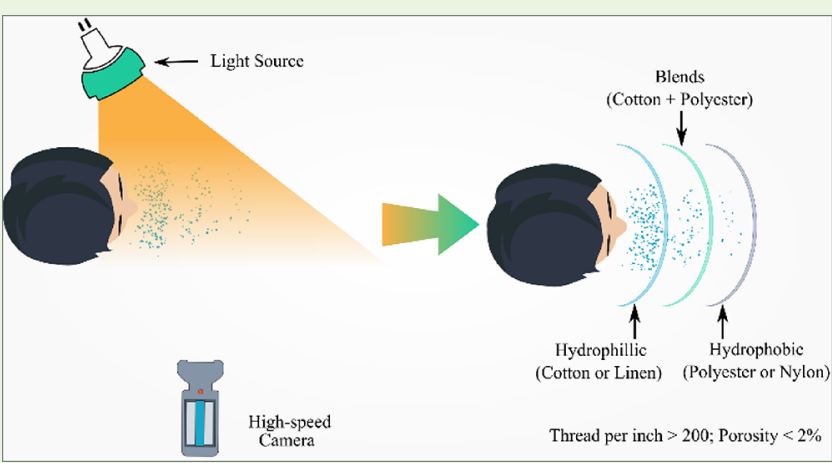
number of layers significantly increases the droplet blocking efficiency, on average by $\sim 20$ times per additional fabric layer. A minimum of three layers is necessary to resemble the droplet blocking performance of surgical masks, and a combination of cotton/linen (hydrophilic inner layer)-blends (middle layer)polyester/nylon (hydrophobic outer layer) exhibited the best performance among overall indicators tested. In an optimum threelayered design, the average thread count should be greater than 200 , and the porosity should be less than $2 \%$. Furthermore, machine washing at $60{ }^{\circ} \mathrm{C}$ did not significantly impact the performance of cloth masks. These findings inform the design of high-performing homemade cloth masks.

KEYWORDS: cloth mask, face masks, respiratory protection, fabrics, droplet blocking, sneeze, water resistance, PPE

\section{INTRODUCTION}

The major mode of transmission of pathogens, including the Severe Acute Respiratory Syndrome Coronavirus 2 (SARSCoV-2), is through respiratory droplets and aerosols generated during speaking, coughing, and sneezing. ${ }^{1,2}$ Pathogen-laden droplets and aerosols play a significant role in transmission of infection. ${ }^{3-5}$ Recent evidence suggests that droplets can travel up to $8 \mathrm{~m}$ horizontally; ${ }^{6,7}$ therefore, face masks are a critical intervention that can be used to protect healthy people and prevent the spread of virus-laden droplets from sick individuals (source control). ${ }^{8-13}$ During the COVID-19 pandemic, more than $75 \%$ of the world's population have been given official guidelines on wearing a mask in public settings. ${ }^{14}$ However, due to the worldwide shortages of medical masks and respirators, the use of homemade cloth masks has been proposed as an alternative. The US Centers for Disease Control and Prevention (CDC) and the World Health Organization (WHO) also recommend the use of homemade cloth masks. ${ }^{9,15}$ However, there is insufficient evidence on the performance of commonly accessible fabrics for the optimal design of cloth masks, especially based on the capacity of blocking human-generated respiratory droplets.
To date, a few well-documented experimental studies have evaluated the performance of common fabrics for designing cloth masks. ${ }^{14,16-31}$ However, most of these studies used pressure-driven artificially generated aerosols and droplets, and there is limited knowledge on the effectiveness of fabrics against human-generated respiratory droplets. Moreover, the size and velocity distributions of droplets together with the viscoelasticity of the respiratory fluid are different from the artificially generated aerosols. ${ }^{20}$ Additionally, relative humidity and exhalation temperature in real scenarios are different from the conditions produced by artificial systems, making it essential to study the efficacy of various fabrics against human-generated respiratory emissions. Note that only three studies have assessed the filtration using human-generated respiratory droplets; however, these were limited to breathing,

Received: March 17, 2021

Accepted: May 11, 2021

Published: May 21, 2021 


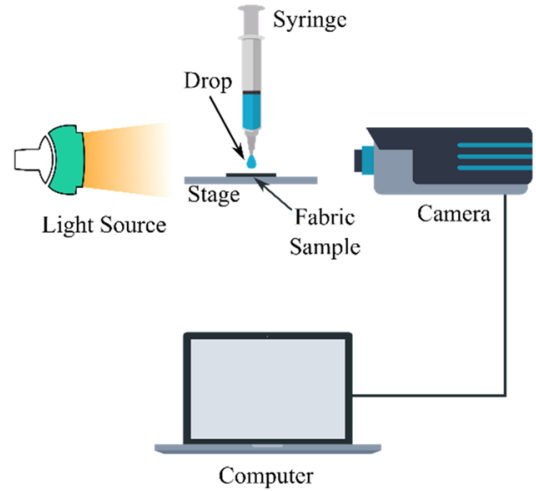

(a)

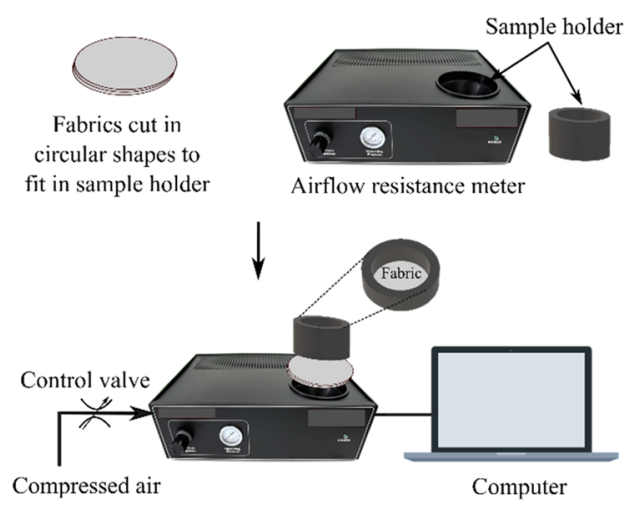

(b)

Figure 1. Schematic representation of the experimental setup for (a) the measurement of water resistance and (b) breathing resistance.

speaking, and coughing only. ${ }^{22,26,27}$ Until recently, no study has evaluated the performance of cloth masks based on the most violent respiratory event-human sneeze. Since sneezing generates more than 100 times the droplets expelled by any other respiratory event, ${ }^{32}$ it is essential to consider events such as human sneezes for a comprehensive evaluation of cloth masks. This study aims to address, for the first time, the minimum number of fabric layers, the fabric composition, and combinations necessary for optimum protection from airborne pathogens. Additionally, the fluid resistance of fabrics, which is very important for determining the optimal position (outer, middle, and inner layers) of fabrics in a cloth mask, has been explored by only one study. ${ }^{20}$ Instead, most studies focus on filtration only. Moreover, there is minimal information on the impact of washing, which is essential for reusing cloth masks, on the performance of the fabrics used in cloth masks.

Accordingly, to address the aforementioned knowledge gaps, we present a comprehensive study evaluating the respiratory droplet blocking efficiency using sneezes by a healthy adult and an image-based flow measurement diagnostic system. Additionally, to provide an optimum design of a cloth mask, we used sessile drop measurements for water resistance, and airflow resistance measurements for breathability. Finally, we also assessed the effect of washing, which is essential for reusing cloth masks, on the droplet blocking efficiency of various fabrics.

\section{MATERIALS AND METHODS}

2.1. Fabric Characterization and Measurement of Water Resistance. To provide a comprehensive database for the efficacy of various materials, 17 different commonly available fabrics, such as cotton, polyester, nylon, linen, silk, and blends having different properties plus a commonly available standard three-layered surgical mask (Bao Thach), were tested. We note that each cloth mask configuration (single-, double-, and triple-layer) was prepared by modifying the CDC recommended quick cut no-sew method (Figure S1).

To test the microstructure, thread count, and porosity, fieldemission scanning electron microscopy (FE-SEM; FEI Nova NanoSEM 230) was used to examine the microscopic structures of fabrics and pores. Fabric samples were coated with $5 \mathrm{~nm} \mathrm{Cr}$ and $30 \mathrm{~nm} \mathrm{Pt}$ using a sputter coater (Leica ACE600) before capturing the images in the backscatter mode (accelerating voltage $15 \mathrm{kV}$, spot size 3.5 ). Thread count and measurement of porosity were done using SEM images.

The water resistance was measured by the change in the contact angle of the water droplet over time utilizing a drop shape analyzer (DSA25 -KRÜSS GmbH, Hamburg). The sessile drop measurement was done at room temperature, where the drop volume and dropping rate were $2 \mu \mathrm{L}$ and $0.16 \mathrm{~mL} / \mathrm{min}$, respectively. The schematic representation of the experimental setup for measuring water resistance is shown in Figure 1a.

2.2. Visualization of the Droplet/Aerosol Blocking Capacity. To test the capability of a fabric to block the spread of respiratory droplets, face masks made from different fabrics were tested against sneezes by a healthy adult ( 30 years of age). Before the study, written informed consent was taken from the subject. Ethical approval for this study was obtained from the University of New South Wales Human Research Ethics Committee (HC180830). We tested for sneezing, which has been documented to generate a large magnitude of droplets/aerosols relative to other activities such as speaking and coughing. ${ }^{33}$ The sneezes were induced by stimulating the mucus membrane of the nasal cavity using tissue paper. For sneezing while wearing a face mask, the subject removed the tissue paper from the nasal cavity and adjusted the mask in position just before the onset of the sneeze (Movie S1). High-speed videos of droplets expelled while wearing different face masks were captured at a resolution of $1920 \times$ 1440 pixels. To capture the videos, an LED-based light source was used along with a spherical lens to adjust the divergence of the light beam. The light was positioned in a forward scatter arrangement, and videos were captured at an exposure of $1000 \mu \mathrm{s}$. With this setup, we obtained high-speed video frames with a resolution of $135 \mu \mathrm{m} /$ pixel. These frames were first preprocessed using the following steps.

2.2.1. Noise Reduction, Calibration, and Distortion Removal. To remove the noise from the captured video first, a background subtraction operation was performed, and then, histogram equalization was performed on all of the frames. The frames were calibrated using a custom calibration target with $2 \mathrm{~mm}$ calibration dots and a dot spacing of $5 \mathrm{~mm}$. An image of the calibration target was captured before capturing the high-speed video, and a transform was created to convert pixel space data to real space. The transform was then used to remove the distortion and to calibrate the images. ${ }^{32}$

2.2.2. Stabilizing the Movement of the Head and Facial Contour Detection. To analyze all of the different frames for droplet spread, it was essential to stabilize the movement of the head during the sneeze. This was performed by applying a two-axis stabilization to the head of the subject. More details of this procedure can be found in our recent study. ${ }^{32}$ Detection of the facial contour is essential to measure the droplet blocking capability of the face masks at a fixed distance from the mouth. This was performed by preprocessing every image in the sequence using pixel intensity manipulation to accentuate the edge, and then, a two-dimensional (2D) convolution was performed to find the gradient in horizontal and vertical directions. ${ }^{34}$ Once gradients were obtained, each row of pixels in an image was scanned for intensity variation to determine the edge of the face. The process was repeated for all of the frames in the captured video. The information of edge location for all of the frames was used to determine the location of the mouth for the image sequence. 
2.3. Evaluation of the Impact of Washing. To assess the reusability, the droplet blocking efficiency of the fabrics was also checked after two cycles of 15 min washing in a washing machine at $60{ }^{\circ} \mathrm{C}$ using a commonly available detergent. ${ }^{9}$

2.4. Breathing Resistance and Fit Testing. Breathing resistance (pressure drop) was measured using a SIGMA airflow resistance meter (Mecanum, S/N:1060-19, Canada) at an operating pressure of $40 \mathrm{psi}$. The fabrics were cut into circular shapes to fit into the sample holder of the airflow resistance meter. The schematic representation of the experimental setup for the measurement of breathing resistance is shown in Figure 1b. Qualitative fit testing of the mask samples was done using a 3M FT-30 fit test apparatus (bitter-denatonium benzoate).

\section{RESULTS AND DISCUSSION}

3.1. Fabric Characterization. Understanding the material, structure, and other properties of fabrics is essential to evaluate their impact on filtration efficiency. ${ }^{14}$ Our samples include various types of cotton $(\mathrm{C} 1-\mathrm{C} 5)$, polyester $(\mathrm{P} 1, \mathrm{P} 2)$, nylon (N1, N2), silk (S1), linen (L1), towel cloth (T1), and blends (B1-B5) of different compositions and properties. Additionally, a surgical mask was used to compare with the fabric samples. The composition, weight, thread count, and porosity of the fabric samples are given in Table 1. SEM images are

Table 1. ID, Composition, GSM, Thread Per Inch (TPI), and Porosity of Different Fabric Samples Used in the Study

\begin{tabular}{|c|c|c|c|c|c|}
\hline $\begin{array}{l}\text { sample } \\
\text { IDs }\end{array}$ & $\begin{array}{c}\text { fabric } \\
\text { composition }\end{array}$ & $\begin{array}{l}\text { weight } \\
\left(\mathrm{g} / \mathrm{m}^{2}\right)\end{array}$ & $\begin{array}{l}\text { threads } \\
\text { per inch }\end{array}$ & $\begin{array}{c}\text { porosity } \\
(\%)\end{array}$ & remarks \\
\hline $\mathrm{C} 1$ & $100 \%$ cotton & 120 GSM & 215 & $\sim 1.5$ & poplin \\
\hline $\mathrm{C} 2$ & $100 \%$ cotton & 100 GSM & 230 & $\sim 1.8$ & sateen \\
\hline C3 & $100 \%$ cotton & 45 GSM & 160 & $\sim 30$ & voile \\
\hline $\mathrm{C} 4$ & $100 \%$ cotton & 170 GSM & 170 & $\sim 3$ & $\begin{array}{r}\text { T-shirt } \\
\text { cloth }\end{array}$ \\
\hline $\mathrm{C} 5$ & $100 \%$ cotton & 140 GSM & 140 & $\sim 8$ & \\
\hline P1 & $100 \%$ polyester & 106 GSM & 205 & $\sim 5$ & \\
\hline P2 & $100 \%$ polyester & 78 GSM & 280 & $\sim 8$ & $\begin{array}{l}\text { sateen } \\
\text { chiffon }\end{array}$ \\
\hline B1 & $\begin{array}{l}64 \% \text { cotton, } 33 \% \\
\text { polyester, } 3 \% \\
\text { spandex }\end{array}$ & 125 GSM & 215 & $\sim 1.2$ & \\
\hline B2 & $\begin{array}{l}65 \% \text { polyester, } \\
35 \% \text { cotton }\end{array}$ & 180 GSM & 170 & $\sim 8$ & \\
\hline B3 & $\begin{array}{l}95 \% \text { cotton, } 5 \% \\
\text { spandex }\end{array}$ & 155 GSM & 200 & $\sim 7.5$ & \\
\hline B4 & $\begin{array}{l}70 \% \text { cotton, } 30 \% \\
\text { silk }\end{array}$ & 40 GSM & 260 & $\sim 15$ & \\
\hline B5 & $\begin{array}{l}60 \% \text { linen, } 40 \% \\
\text { cotton }\end{array}$ & 125 GSM & 130 & $\sim 8.5$ & \\
\hline N1 & $100 \%$ nylon & 80 GSM & 220 & $\sim 1.6$ & \\
\hline $\mathrm{N} 2$ & $100 \%$ nylon & 50 GSM & 150 & $\sim 15$ & \\
\hline L1 & $100 \%$ linen & 165 GSM & 110 & $\sim 7$ & \\
\hline S1 & $100 \%$ silk & 60 GSM & 260 & $\sim 10$ & \\
\hline $\mathrm{T} 1$ & $\begin{array}{l}95 \% \text { cotton, } 5 \% \\
\text { nylon }\end{array}$ & 380 GSM & & & $\begin{array}{l}\text { towel } \\
\text { cloth }\end{array}$ \\
\hline M & $\begin{array}{l}100 \% \\
\text { polypropylene }\end{array}$ & & & & $\begin{array}{c}\text { surgical } \\
\text { mask }\end{array}$ \\
\hline
\end{tabular}

shown in Figure 2, and Figure S2 represents the microscopic structures, weaving patterns, compactness, and pores of the fabric samples. The digital photographs of the samples are shown in Figure S3.

Fabrics had various weights, ranging from 40 to $380 \mathrm{~g} / \mathrm{m}^{2}$. The thread counts and porosity were found to be in the ranges of 110-280 threads per inch (TPI) and $1.2-30 \%$, respectively. Most of the fabric samples had a porosity of between 1 and
$10 \%$. High thread count, fineness of the weave, and low porosity of the fabrics are important for filtration because droplets can pass through the pores, and interfiber spaces. ${ }^{20}$ However, among the cotton samples, C1 (poplin) and C2 (sateen) had the highest thread count (215 TPI and 230 TPI, respectively), and hence, the lowest porosity (both $\sim 1.5 \%$ ). Between the polyesters, P1 had a higher weight (106 GSM) and lower porosity $(\sim 5 \%)$, whereas $\mathrm{P} 2$ had a higher thread (280 TPI) count and tight weave. The weight, thread count, and porosity of nylon N1 were found to be 60 GSM, $120 \mathrm{TPI}$, and $\sim 1.6 \%$, respectively, which are better than the sample N2. Among the blends, B1 had the lowest porosity $(\sim 1.2 \%)$ with moderate weight (125 GSM). Although B4 had a higher thread count than B1, its porosity was very high $(\sim 15 \%)$. The thread counts and porosity of L1 and S1 were 110 TPI, $7 \%$ and 260 TPI, $\sim 10 \%$, respectively. T1 (towel cloth) was very thick and hence weighed 380 GSM. Note that the thread counts and porosity measurement of the towel and the outer layer of the surgical mask were not calculated because of their bulky nature, random overlapping network, and pleating of fibers.

3.2. Water Resistance. It is well established that respiratory droplets are water-based. ${ }^{35}$ Hence, the water resistance of a fabric filter medium is critical to preventing undesirable attachment and absorption of pathogen-laden droplets and aerosols. Specifically, the water resistance of fabric is correlated with droplet blocking efficiency. ${ }^{20}$ Fabrics with a high water resistance are capable of building a static charge and thus improving the filtration. ${ }^{18}$ Water resistance is very important in determining the position (outer, middle, and inner layers) of the fabrics in a mask. Outer layer fabrics should be hydrophobic to protect the inner layers from being contaminated by infectious fluid droplets. ${ }^{36}$ On the other hand, the inner layer should be hydrophilic to readily absorb the expelled fluids and reduce humidity for the wearer. ${ }^{13,37}$ The surface chemistry of the fabrics determines the hydrophilic or hydrophobic nature. ${ }^{18}$ We assessed the water resistance of the fabric samples by measuring the variation of water contact angles over time at the junction of the drop contour and the fabric surface. The experimental setup and the results are shown in Figures 1a and 3. To this end, we captured real sessile drop images at the junction of the drop contour and the fabric surface, which are shown in Figure 4.

Our results revealed that the pure cotton samples $(\mathrm{C} 1-\mathrm{C} 5)$, which is one of the most common choices for making homemade cloth masks, showed very rapid water-absorbing capacity. ${ }^{16}$ Specifically, the water droplets were absorbed within 1-10 s. This rapid absorption is associated with a large number of hydroxyl groups on the cotton surface and the capillary action. ${ }^{38}$ Linen (L1) and silk (S1) also showed high hydrophilicity because their polymeric structure is mainly composed of cellulose and amino acid monomers, respectively, having negatively charged functional groups. ${ }^{39,40}$ On the other hand, polypropylene (the outer layer of a surgical mask, M), nylon (N1, N2), and polyester (P1) showed very high water resistance. In all of the cases, the water droplets were not absorbed even after $300 \mathrm{~s}(5 \mathrm{~min})$. After $5 \mathrm{~min}$, the average contact angles of M, P1, and N1 were found to be 128, 119, and $118^{\circ}$, respectively. Polypropylene is more hydrophobic than nylon and polyester because it has only a hydrocarbon chain. ${ }^{18}$ However, P2 showed a higher water absorption, which likely due to the fact that the fabric has gone through hydrophilic surface modification. ${ }^{41,42}$ The results showed that the blends B3 (95\% cotton), B4 (70\% cotton, 30\% silk), and 
(a)

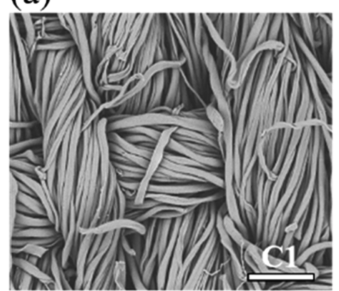

(f)

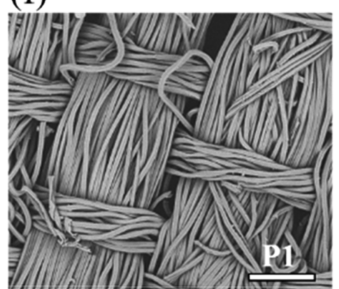

(k)

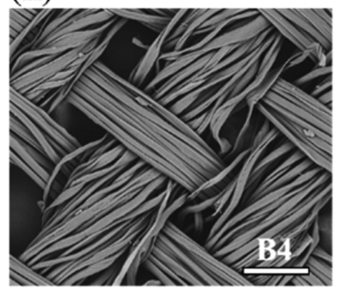

(b)

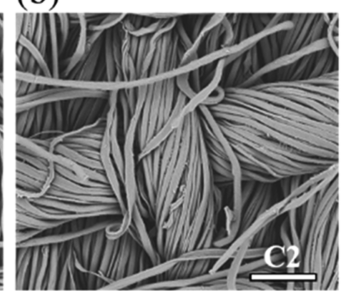

(g)

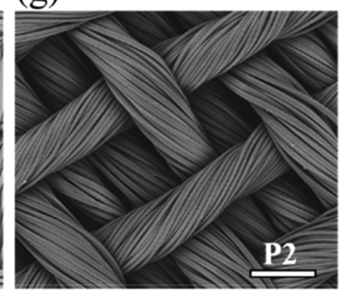

(1)

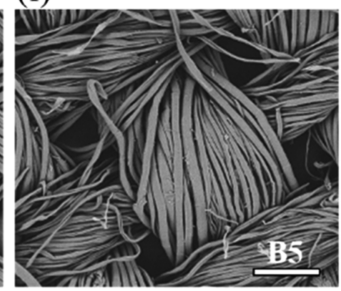

(p)

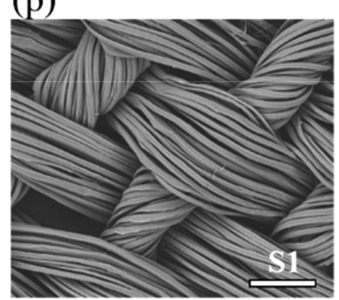

(c)

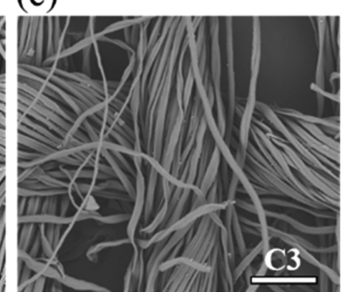

(h)

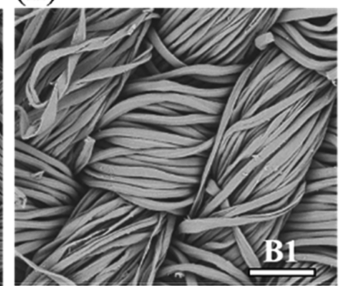

(m)

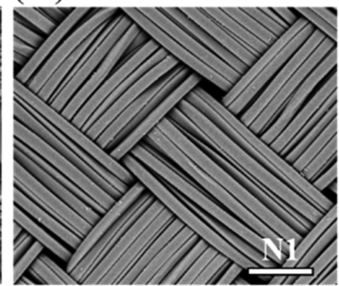

(q)

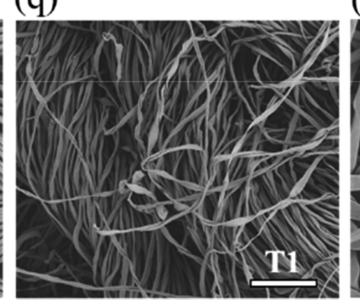

(d)

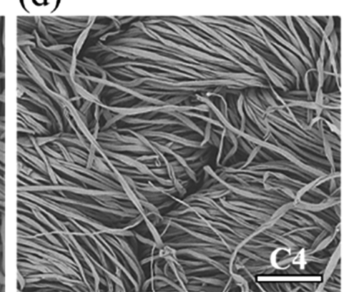

(i)
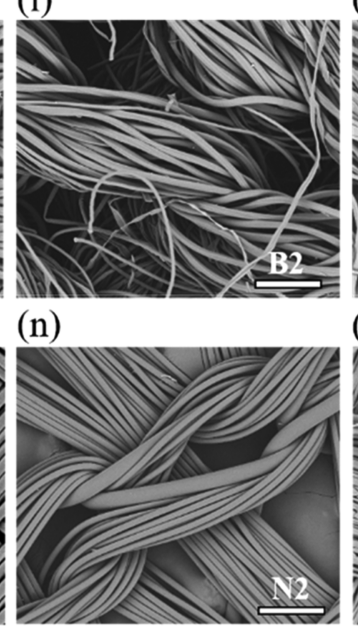

(r) (n)

(e)

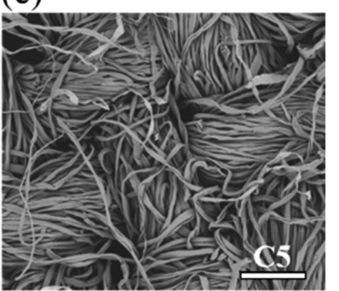

(j)

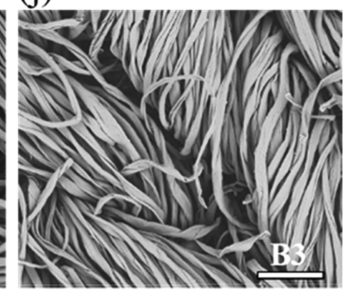

(o)
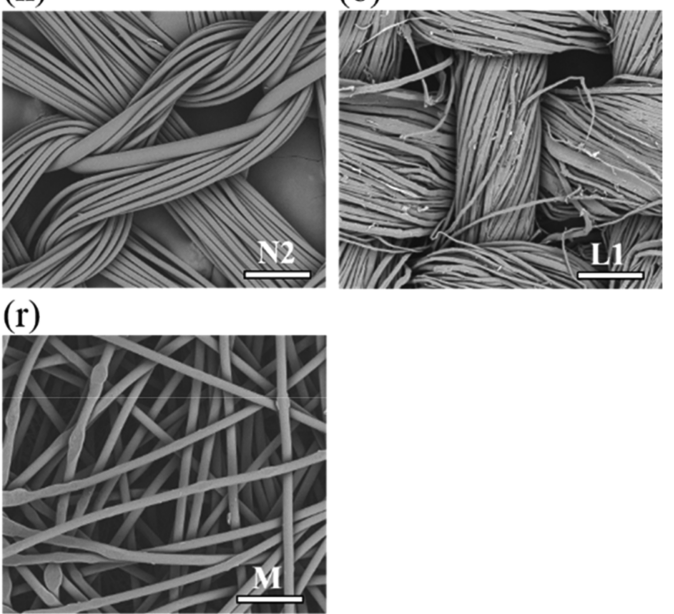

Figure 2. Field-emission scanning electron microscopy (FE-SEM) images of various fabric samples showing the microscopic structures and pores $(\mathrm{a}-\mathrm{q})$. The white bars at the bottom right corner correspond to $200 \mu \mathrm{m}$. (r) Top layer of the surgical mask.

B5 (60\% linen, $40 \%$ cotton) had a lower water resistance property than B1 (64\% cotton, 33\% polyester, 3\% spandex) and B2 (65\% polyester, 35\% cotton) because of their composition. As cotton, silk, and linen all are very hydrophilic, B3, B4, and B5 showed low water resistance. On the other hand, the presence of hydrophobic polyester made B1 and B2 more water resistant than the other blends. Due to the presence of $5 \%$ nylon, T1 (towel cloth) exhibited some degree of hydrophobic nature, with the water droplets absorbed after $30 \mathrm{~s}$.

3.3. Droplet Blocking Capability of a Single-Layered Cloth Mask. To assess the efficiency of each cloth mask under a strong respiratory exhalation, a sneeze (while wearing a mask) was captured by a high-speed camera. The setup used to capture high-speed videos of sneezing is depicted in Figure 5a. The high-speed video was analyzed by a tailored image-based flow measurement diagnostic system, which is described in Section $2 .^{32}$

To assess the number of droplets expelled and the spread of these droplets, the mean intensity of all of the vertical pixels at different distances from the mouth of the subject for each frame in the high-speed video was examined across the whole duration of a sneeze (Figure S4). To quantify the droplet/ aerosol blocking capability of the face covering, the average intensity $(I)$ computed for a $2 \mathrm{D}$ area $(1 \mathrm{~cm}$ wide rectangle) among all of the frames for the duration of the sneeze at a fixed distance of $2 \mathrm{~cm}$ from the subject was chosen (dashed rectangle in Figure 7). This eliminated the effect of erroneous data in close proximity to the mouth of the subject, and in doing so, this metric provides a simple yet quantifiable relative measure of the number of droplets, where a larger number of droplets corresponds to a higher magnitude of the parameter $I$. The results of the droplet blocking capability of the singlelayered fabrics are shown in Figure 6a. Note that a normalized value of $I$ is used in the figures for a better comparison of fabrics and their combinations. The value ranges from 0 to 1 , with 0 being the best and 1 being the worst fabric/combination in terms of droplet blocking capacity. For closer inspection, Figures 7 and S5 show the frames at $100 \mathrm{~ms}$ after the onset of a sneeze for all of the cases of single-layered fabrics. These frames show the light scattered by the droplets leaking through the single-layered face mask. It should be noted that before performing the experiments to ensure consistency between sneezes by the volunteer, a set of multiple independent sneezes without any face mask was first captured. We found that the variation in the average intensity between different sneezes by the subject was $<4 \%$ (Figure $5 b$ ), which implies that the number of droplets expelled from different sneezes is mostly consistent for this volunteer. 


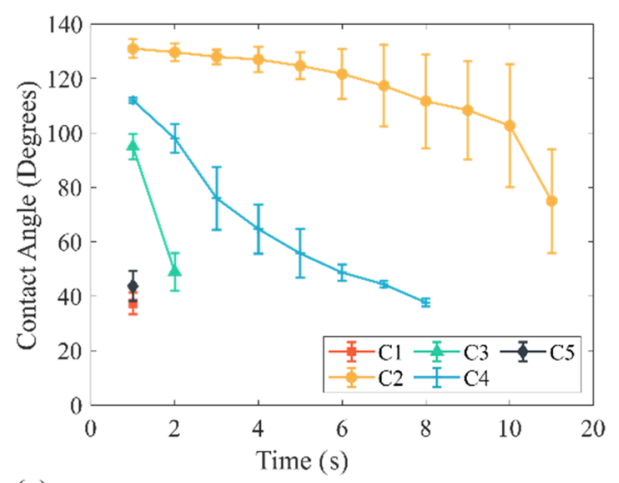

(a)

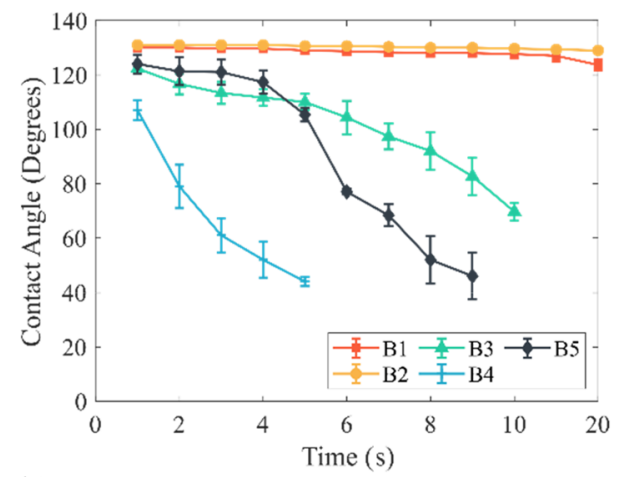

(c)

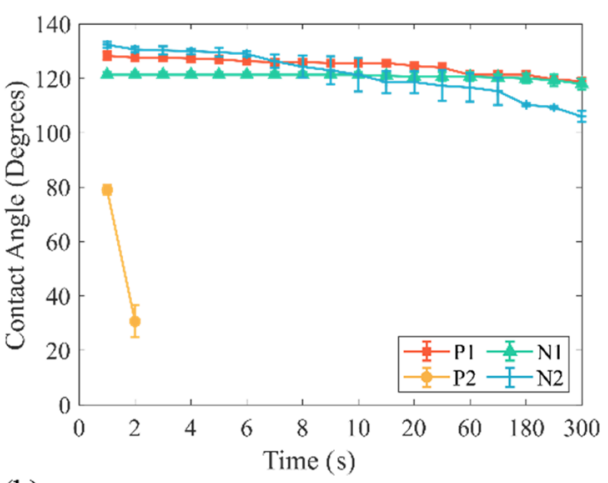

(b)

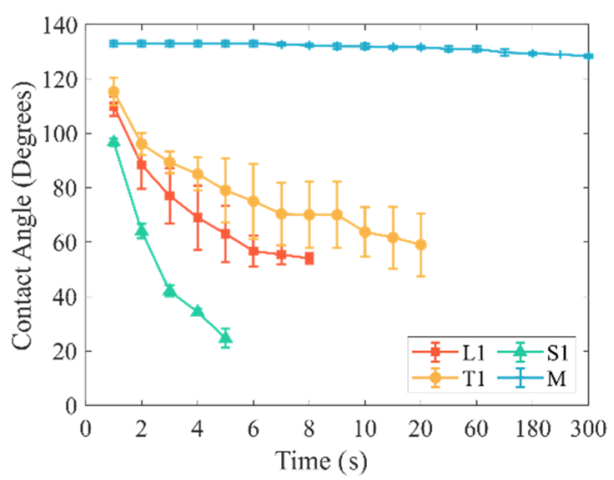

(d)

Figure 3. Water resistance property of various fabrics measured by variation of water contact angles with time at the junction of the drop contour and the fabric surface. (a) Cotton fabrics, (b) polyester and nylon fabrics, (c) fabric blends, and (d) others (silk fabric, linen fabric, towel cloth, and a surgical mask).

Droplets and aerosols are captured by the fabrics mainly by diffusion (aerosols with Brownian motions), interception (small droplets within one droplet radius of the fabrics), impaction (droplets $>5 \mu \mathrm{m}$, leaving streamline due to high inertia), and electrostatic interaction (negatively charge droplets attracted by positively charged fabrics). ${ }^{43-45}$ Besides these, the magnitude of captured droplets is dependent on the complex interplay among the chemistry of fabric materials, porosity, thread count, weight per unit, and weaving. ${ }^{14}$ Our results reveal that the droplet blocking efficiency of the cotton samples is in the following order: $\mathrm{C} 1>\mathrm{C} 4>\mathrm{C} 2>\mathrm{C} 5>\mathrm{C} 3$. $\mathrm{C} 1$ showed the highest filtration efficiency maybe because of the lowest porosity $(\sim 1.5 \%)$ and tight weave with higher thread counts (215 TPI) than those of C3, C4, and C5. Although C4 (T-shirt cloth) has higher porosity ( 3\%) than C2 $(\sim 1.8 \%)$, it demonstrated higher efficiency, possibly due to higher weight $\left(170 \mathrm{~g} / \mathrm{m}^{2}\right)$ than C2 $\left(100 \mathrm{~g} / \mathrm{m}^{2}\right)$. Similarly, in the case of polyester, owing to the lower porosity and higher weight, P1 showed more efficiency than P2. In the case of blends (B1-B5), B1 and B2 having cotton and polyester in their composition (a mixture of hydrophilic and hydrophobic) showed better performance than other blends having cotton, silk, and linen (all are hydrophilic). This is likely caused due to more challenging disruption of the surface tension of hydrophobic fabrics by the droplets than that for hydrophilic fabrics. ${ }^{20}$ B1 exhibited the lowest porosity, while B2 had the highest weight/unit. Between nylon samples, it is evident that N1 has a higher droplet blocking capacity due to a combination of its compact structure and lower porosity, higher thread counts, and weight than N2. However, as a class of hydrophilic fabric linen, L1 ( 7\% porosity, 110 TPI, and
165 GSM) exhibited much better efficiency than silk, S1 ( $\sim 10 \%$ porosity, $160 \mathrm{TPI}$, and $60 \mathrm{GSM}$ ), which is close to the efficiency of $\mathrm{C} 1$. Towel cloth (T1) was very thick and bulky (380 GSM); hence, it was observed to be very effective in blocking droplets; however, it was found to be very uncomfortable to wear as a mask.

The results reveal that lower porosity, water resistance, and higher weight/unit have a positive impact on droplet blocking efficiency, which is consistent with other related studies. ${ }^{16,20}$ When droplets attempt to squeeze through smaller pores of fabrics, they need more energy than to pass through large pores due to the higher surface tension barrier with the interfacial energies of the water droplet, air, and the fabric. ${ }^{20}$ Viscous stresses in the fluid droplets are also higher.

3.4. Droplet Blocking Capability of Multilayered Cloth Masks. From our comprehensive testing of singlelayered fabrics, we selected the five best fabrics based on the performances of both water resistance and droplet blocking efficiency. As mentioned earlier, for designing an effective cloth mask, both hydrophilic (for the inner layer) and hydrophobic (for outer layer/middle layer) fabrics are required. Therefore, we selected two hydrophilic fabrics (cotton, C1, and linen, L1), two hydrophobic (polyester, P1, and nylon, N1), and one blend (B1). Using the selected 5 fabrics, we made 15 different combinations of 2-layered cloth masks and 15 of 3-layered masks (summarized in Table S1). We evaluated the droplet/ aerosol blocking efficiency of all 30 different combinations. A high-speed visualization of droplet blocking efficiency with the fluctuation of the average intensity for one representative scenario for each layer is provided in Movie S2. Droplet blocking efficiency of two-layered combinations and three- 


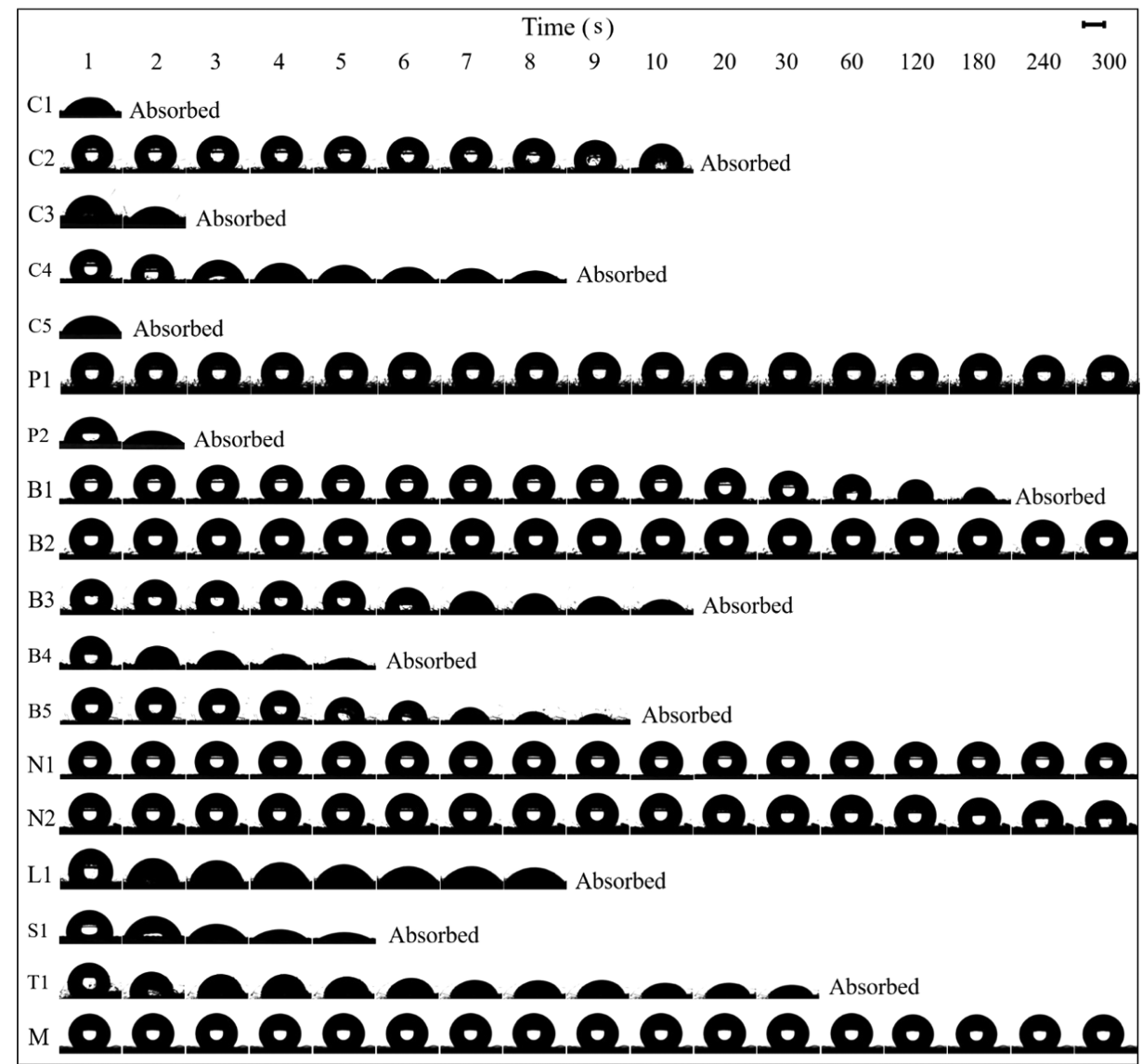

Figure 4. Real sessile drop images at the junction of the drop contour and the fabric surface. The figure shows the water resistance property of all of the different fabric samples over time. The scale bar at the top right corner of the images corresponds to $0.5 \mathrm{~mm}$.

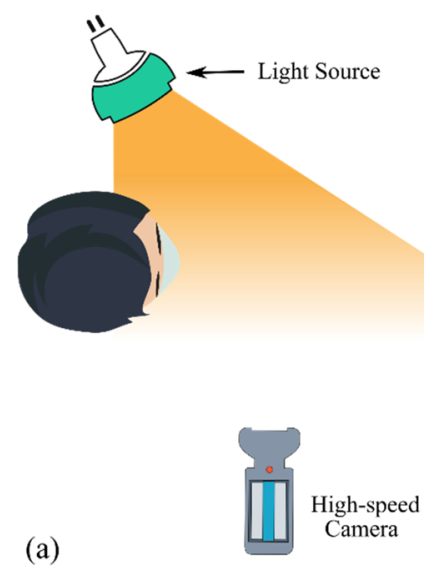

(a)

Figure 5. (a) Schematic of the setup used to capture high-speed videos of sneezing. (b) Variation of the average intensity with the distance from the mouth for five different sneezes from the subject.

layered combinations and blocking efficiency as a function of the number of layers are shown in Figures $6 \mathrm{~b}, \mathrm{c}$ and 8 , respectively. The corresponding images of the blocking efficiency of multilayer fabrics are shown in Figures 7, S6, and S7.

From the results, it can be observed that increasing the number of layers increases the droplet blocking capability, which is consistent with the results of other studies ${ }^{16-18}$ but now quantified through detailed droplet imaging. For twolayered combinations, the average intensity values measured at $2 \mathrm{~cm}$ from the mouth of the subject indicate that a

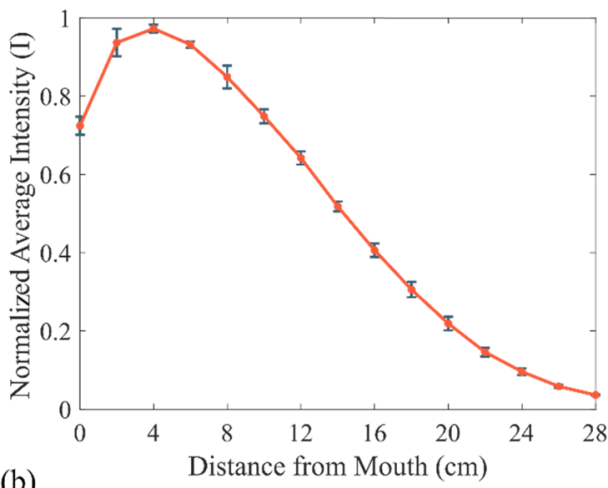

(b)

combination of cotton and blend $(\mathrm{C} 1-\mathrm{B} 1)$, cotton and nylon $(\mathrm{C} 1-\mathrm{N} 1)$, two layers of the blend $(\mathrm{B} 1-\mathrm{B} 1)$, blend and nylon $(\mathrm{B} 1-\mathrm{N} 1)$, or two layers of cotton $(\mathrm{C} 1-\mathrm{C} 1)$ performed better than other combinations. The low porosity values of $\mathrm{C} 1$, B1, and N1 can explain these performances. Most of the blend combinations showed good performance. This is due to the collective influence of both mechanical and electrostatic filtrations in blends, which makes it better filter media than pure fabrics. ${ }^{16}$ Although nylon has similar porosity, two-layered nylon $(\mathrm{N} 1-\mathrm{N} 1)$ did not perform as well, which implies that 


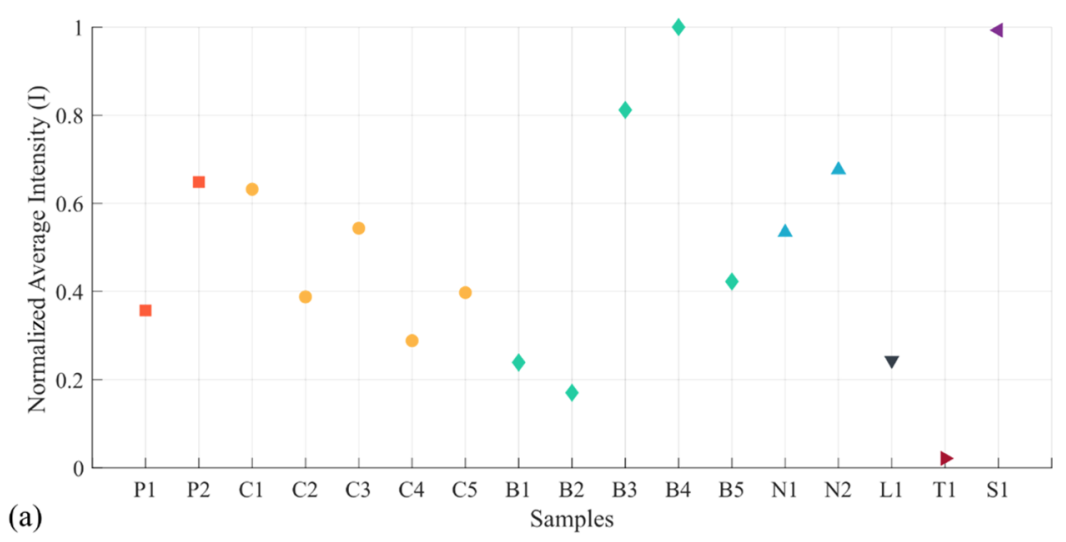

(a)
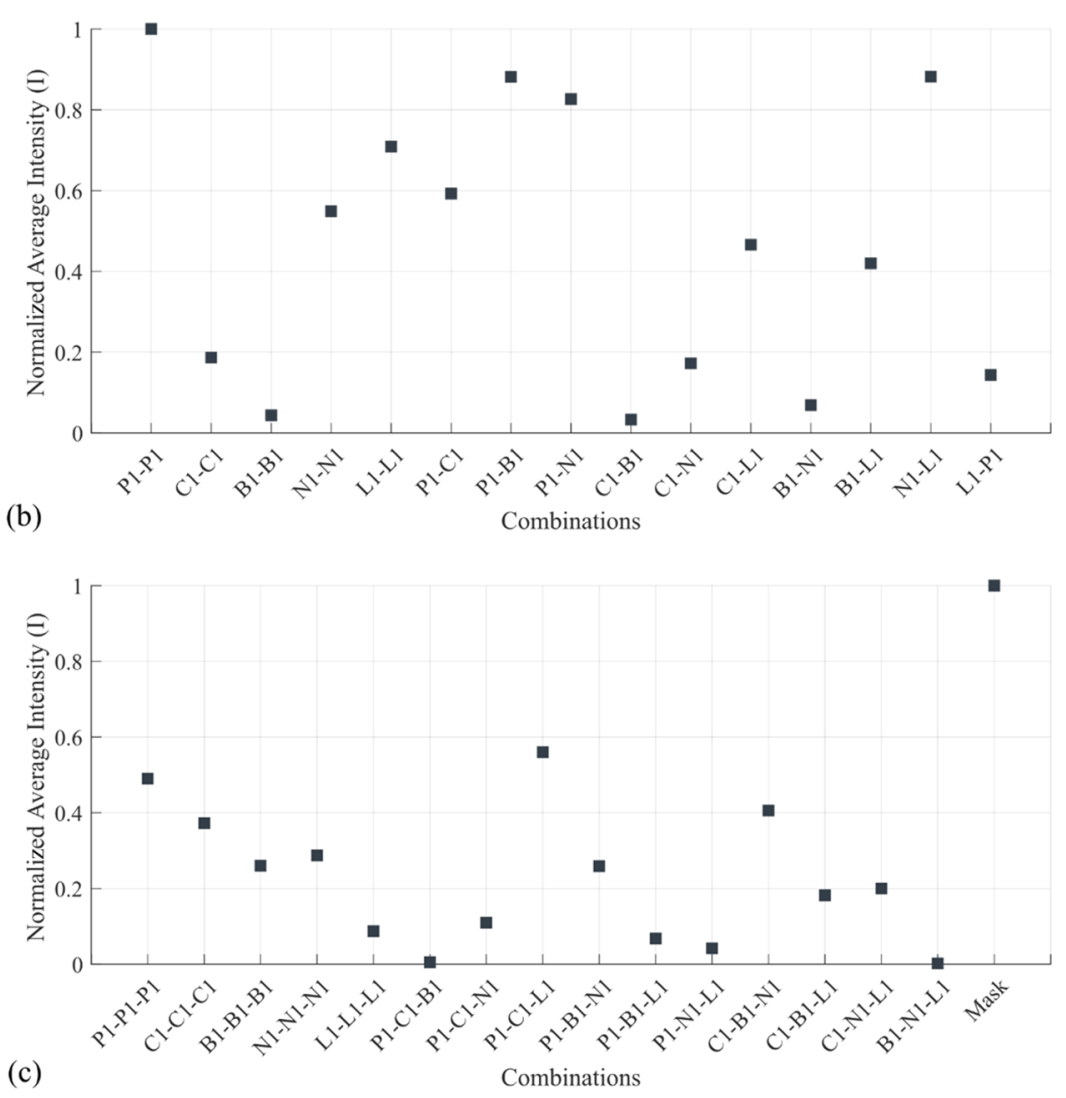

Figure 6. Droplet blocking capability of (a) single-layered face masks, (b) two-layered face masks, and (c) three-layered face masks quantified through image analysis of droplets expelled in sneezes.

the presence of a hydrophilic fabric is important when selecting fabrics for face mask design.

In the case of three-layered combinations, all of the combinations were comparable in blocking the droplets and provided a strong degree of blockage for all combinations. In particular, the combination of cotton-blend-polyester (P1$\mathrm{C} 1-\mathrm{B} 1)$ and linen-blend-nylon (B1-N1-L1) performed the best. Average intensity values of these combinations indicated a negligible number of droplets leaking from the masks. To capture the overall trend of the results, a function of the number of layers, Figure 8 presents all of the results with the vertical axis representing the normalized average intensity as a logarithmic scale. This reveals an approximate improvement of more than 20-fold in the average droplet blocking capability per additional layer. There are several factors responsible for the significant increase in droplet blocking capacity. In particular, when multiple layers are used, the effective porosity for droplet penetration reduces substantially due to pore misalignment, which also leads to high droplet blocking efficiency. ${ }^{20}$ Interlayer friction of fabrics also may contribute as it generates static charge in the hydrophobic fabrics. ${ }^{16,18}$ The charged fabrics can attract the freshly generated charged droplets/aerosols, thus increasing the filtration efficiency. ${ }^{46}$ Dissipation of energy and loss of momentum of the sneeze droplets while passing through each layer are other possible reasons for the increase in the blocking efficiency. ${ }^{20}$ We note that the three-ply surgical mask performed worse than all three-layered fabric combinations, which can also be observed visually in Figure S7. Nevertheless, it still provided a very good degree of protection compared to single-layered or two-layered options. 

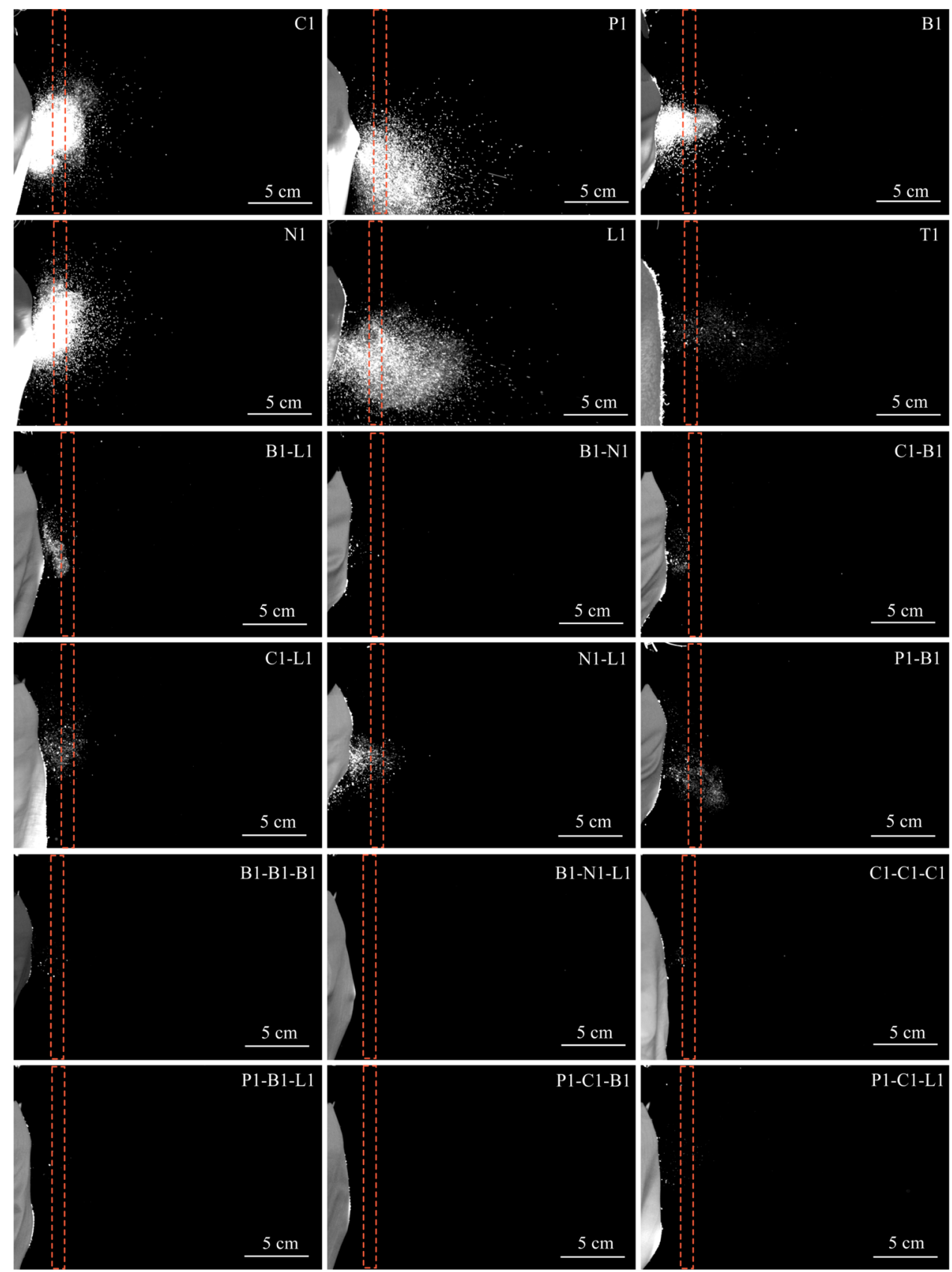

Figure 7. Selected frames from the high-speed video for single-layered, two-layered, and three-layered face masks at $100 \mathrm{~ms}$ after the onset of a sneeze. The red dashed rectangle shows the $2 \mathrm{D}$ area $(\sim 2 \mathrm{~cm}$ from the mouth) where intensity is measured.

\subsection{Droplet Blocking Efficiency of the Selected} Fabrics After Washing. In a pandemic where there is an acute scarcity of face masks, people may need to decontaminate and reuse cloth masks. Washing is the most common and feasible way to decontaminate a homemade cloth mask and is essential after every use. Ideally, the fabrics should retain their filtration properties after washing. Accordingly, we tested and quantified the droplet blocking efficiency of the selected fabrics after two cycles of 15 min washing in a machine at $60{ }^{\circ} \mathrm{C}$. From Figure 9, it can be observed that there was no significant change in the performance of the fabrics other than cotton (C1) and polyester (P1). The increase in performances of $\mathrm{C} 1$ and $\mathrm{P} 1$ can be explained by the temperature $\left(60^{\circ} \mathrm{C}\right)$ and mechanical agitation in the washing machine, which causes consolidation and shrinkage of the fabric and decreases the porosity and tightens the weave. Note that the droplet blocking efficiency was tested only after two washes, and the results may differ for multiple washing cycles.

3.6. Breathing Resistance and Fit. In the present work, breathing resistance is quantified as the air pressure drops across a filter medium. Specifically, a lower pressure drop indicates good breathability and comfort. Hence, it is very important to keep the pressure drop as low as possible while still maintaining the required filtration efficiency. ${ }^{36}$ According to the US National Institute for Occupational Safety and Health (NIOSH), the initial exhalation and breathing resistance of a surgical mask/respirator at an airflow rate of $85 \mathrm{~L} / \mathrm{min}$ should not exceed the limits of 25 and $35 \mathrm{~mm} \mathrm{Hg}$, respectively. ${ }^{36}$ We investigated the pressure drop of all our single-layered, two-layered, and three-layered combinations, 


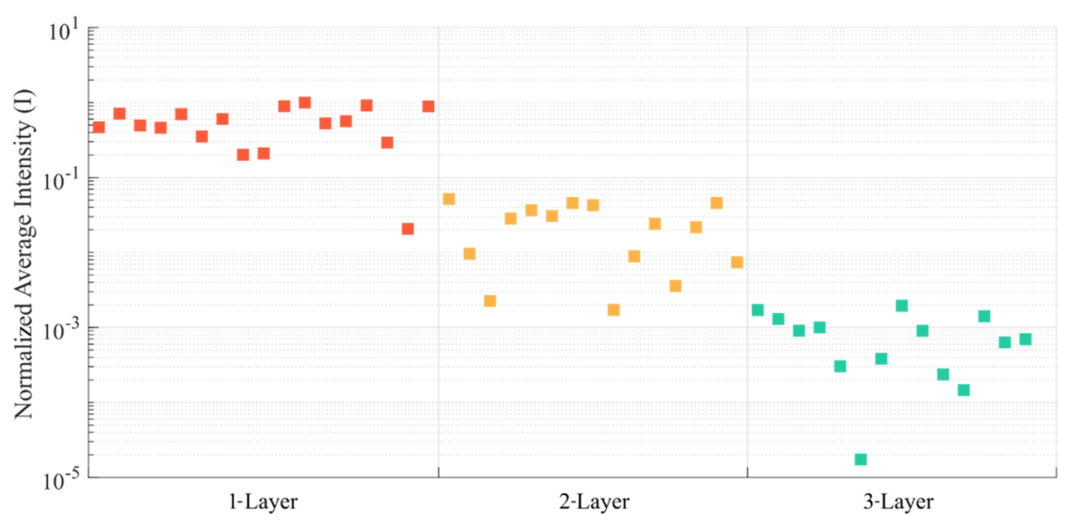

Figure 8. Droplet blocking efficiency as a function of the number of layers, and the vertical axis shows the logarithmic scale to highlight $>20$-fold improvement for each additional layer.

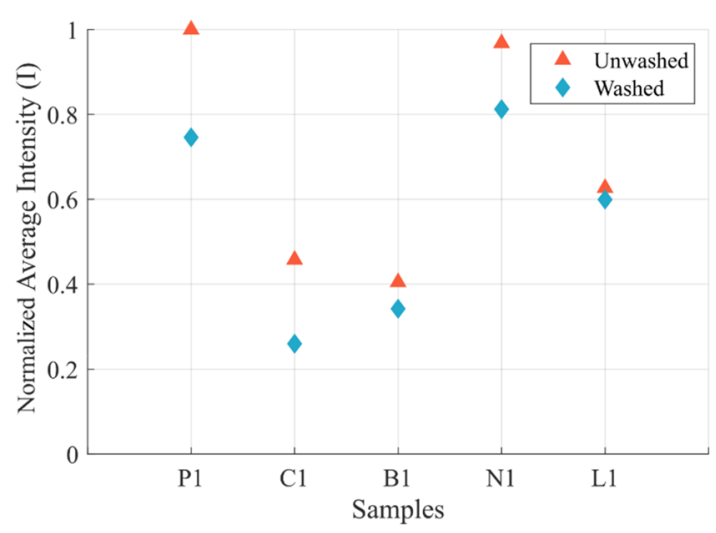

Figure 9. Impact of washing and reusing masks on the droplet blocking capability of fabrics used for making various combinations of two and three-layers.

and the results are presented in Figure 10 (see also Tables S2 and $\mathrm{S} 3$ ).

Among the single-layered samples, B1 performed the worst with a pressure drop of $5.56 \mathrm{~mm} \mathrm{Hg}$, and $\mathrm{L} 1$ performed the best with a pressure drop of $0.72 \mathrm{~mm} \mathrm{Hg}$. This could be explained by the higher porosity in $\mathrm{L} 1$ and $\mathrm{B} 1$ having the lowest porosity among all of the samples. Similar trends can be observed among two-layered and three-layered combinations, where $\mathrm{B} 1-\mathrm{B} 1$ and $\mathrm{B} 1-\mathrm{B} 1-\mathrm{B} 1$ showed the maximum pressure drop, while $\mathrm{L} 1-\mathrm{L} 1$ and $\mathrm{L} 1-\mathrm{L} 1-\mathrm{L} 1$ showed the least value. It is worth noting that all of the samples are within the lower pressure drop limit of $25 \mathrm{~mm} \mathrm{Hg}$ at $85 \mathrm{~L} / \mathrm{min}$, as recommended by NIOSH. ${ }^{36}$ Hence, any of the combinations based on the droplet blocking capacity and water resistance properties can be chosen as the optimum combination for an effective homemade cloth mask.

We performed the qualitative fit testing of all of the threelayered combinations and the surgical mask. The digital photograph of fit testing is shown in Figure S8. None of these combinations and the surgical mask have passed the fit testing. This is because, unlike respirators (such as N95), the construction and design of cloth masks and surgical masks are not intended to tightly fit the face. They are used to prevent respiratory droplets and bodily fluid splashes from reaching the mouth and the nose of the wearer and help reduce and/or control at the source the spread of respiratory droplets from the person wearing the mask. However, some studies recommend nylon stocking over the cloth mask or using a mask brace made of rubber bands to improve the fit. ${ }^{36}$ Detailed further studies are necessary to improve the fit of cloth and surgical masks.

3.7. Comparative Evaluation of Three-Layered Cloth Masks. As the three-layered combinations performed similarly to the surgical mask in terms of droplet blocking efficiency, all the three-layered combinations are visually assessed against each other based on the droplet blocking efficiency, breathing resistance, and contact angle ratio in Figure 11 to evaluate the relative performance and to help the society navigate their choices on making homemade cloth masks. Here, the "contact angle ratio" is the ratio of the contact angle of the water droplets on the outer-layer fabric surface and the inner-layer fabric surface. For the proper selection of fabrics for cloth

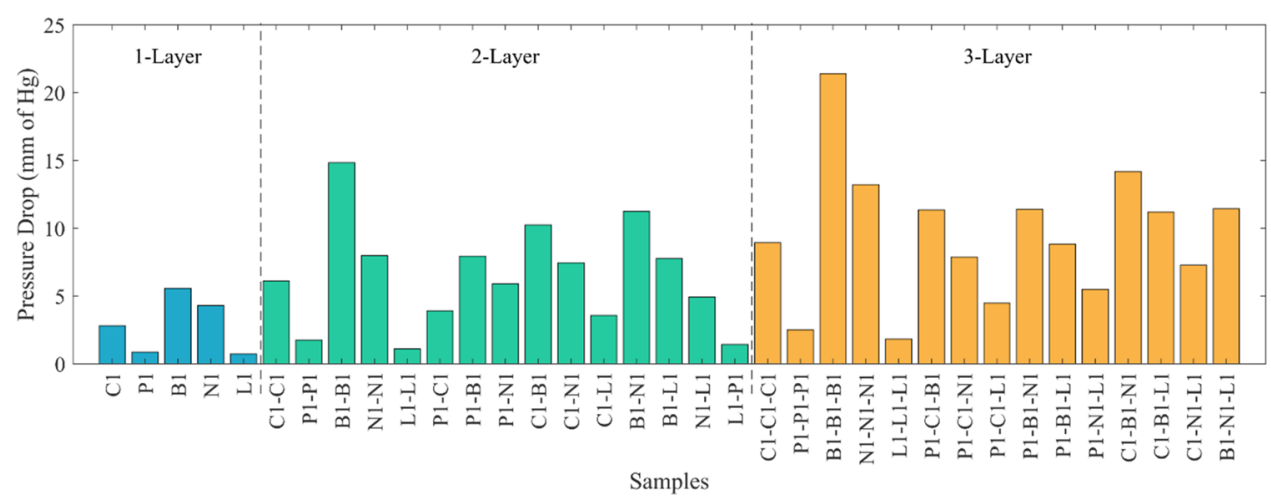

Figure 10. Pressure drop $(\mathrm{mm}$ of $\mathrm{Hg})$ at $85 \mathrm{~L} / \mathrm{min}$ across single-layered and different combinations of two-layered and three-layered cloth masks. 


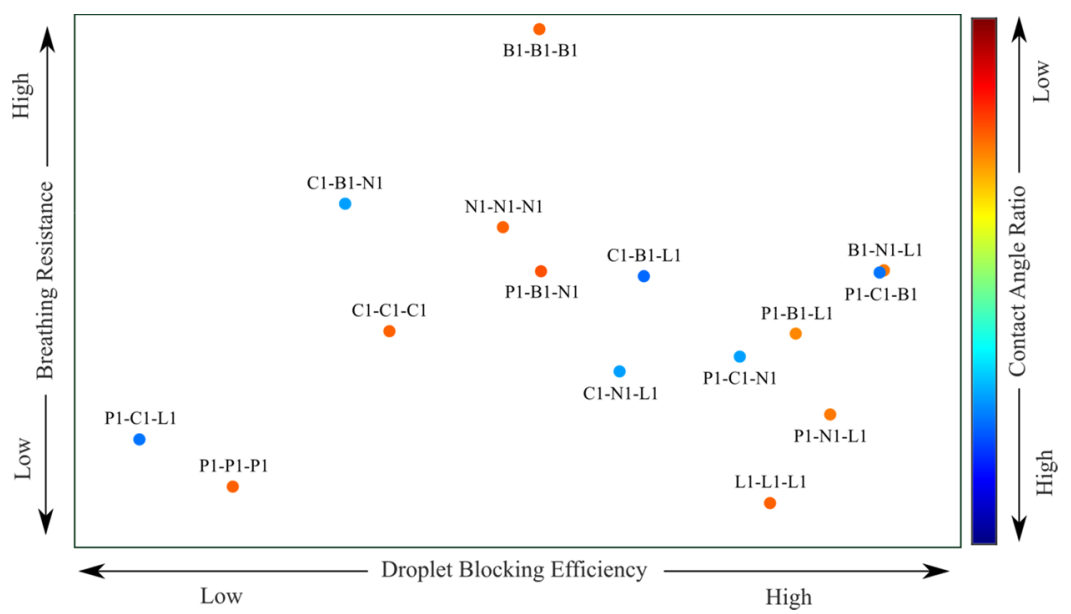

Figure 11. Comparative evaluation of different three-layered combinations based on the droplet blocking efficiency, breathing resistance, and contact angle ratio. The contact angle ratio is the ratio of the contact angle of the water droplets on the outer-layer fabric surface and the inner-layer fabric surface. A high magnitude of this ratio corresponds to a better combination for water resistance.

masks, the contact angle of both the outer and inner layers is equally important. Outer-layer fabrics should be water-resistant (higher contact angle) to protect the inner layers from being contaminated by infectious fluid droplets. On the other hand, the inner layer should be water-absorbing (low contact angle) to readily absorb the expelled fluids and reduce humidity for the wearer. A higher magnitude of the contact angle ratio corresponds to a higher water resistance capacity of the outerlayer fabric when compared to the inner layer. As the inner layer should be less water-resistant (lower contact angle) and the outer layer should be more water-resistant (higher contact angle), a higher ratio corresponds to a better combination. Among all of the tested scenarios, combinations of $\mathrm{P} 1-\mathrm{C} 1-\mathrm{B} 1$ and $\mathrm{B} 1-\mathrm{N} 1-\mathrm{L} 1$ showed the best results in terms of droplet blocking efficiency, whereas L1-L1-L1 and P1-P1-P1 showed the least breathing resistance. On the other hand, $\mathrm{P} 1-\mathrm{C} 1-\mathrm{B} 1, \mathrm{~B} 1-\mathrm{N} 1-\mathrm{L} 1$, and $\mathrm{P} 1-\mathrm{C} 1-\mathrm{B} 1$ showed a higher contact angle ratio. However, if we take all of the parameters into consideration, then $\mathrm{P} 1-\mathrm{C} 1-\mathrm{B} 1$ is the best choice.

\section{CONCLUSIONS}

Homemade cloth masks have become critical during the COVID-19 pandemic due to shortages of disposable medical masks and respirators; hence, it is essential to address the research gaps around the optimal design of cloth masks such as the lack of information about violent respiratory events such as a human sneeze. To address this, here we present a comprehensive study testing the respiratory droplet blocking efficiency (generated during a human sneeze), water resistance, washability, and breathability of different layers and combinations of fabrics to design an effective cloth mask. Results from our image-based analysis reveal that a cloth mask should be made of at least three layers (inner layer-cotton/linen, middle layer-blends of polyester-cotton, and outer layerpolyester/nylon). In the three-layered combinations, the average thread count should be $>200$, and the porosity should be as low as possible $(<2 \%)$. Based on these findings, our recommended design is schematically depicted in Figure S9.

We found that increasing the number of layers and the use of fabric blends significantly enhances the sneeze droplet blocking efficiency. On average, the droplet blocking efficiency improved by $\sim 20$ times per additional fabric layer. A minimum of three layers is necessary for a cloth mask to resemble the droplet blocking performance of the surgical mask while not exceeding the threshold of breathing resistance suggested by $\mathrm{NIOSH}$ - in fact, some of the three-layered cloth masks outperformed a three-layered surgical mask. Among all of the tested scenarios, combinations of cotton (inner layer)-blends (middle layer)-polyester (outer layer), and linen (inner layer)-blends (middle layer)-nylon (outer layer) showed the best results in terms of droplet blocking efficiency. Our study also revealed that there is no substantial change in the performance of the fabrics after two cycles of machine washing, which indicates that a cloth mask can be safely washed for decontamination and reused without affecting the droplet blocking performance at least for a few washing cycles. These results and visualizations ${ }^{47}$ will assist people in preparing effective homemade cloth masks during the ongoing COVID19 pandemic and future epidemics. Moreover, the quantitative measures provide valuable information on the efficiency of droplets spread through masks in general. Facial fit is also an important determinant of the effectiveness of masks, but cloth and surgical masks are not designed to fit, which may reduce their effectiveness. We note that the present study assesses the respiratory droplet blocking performance of different cloth masks based on sneezes from a single healthy adult. Future studies with larger sample size and different age groups are planned to explore this further.

\section{ASSOCIATED CONTENT}

\section{SI Supporting Information}

The Supporting Information is available free of charge at https://pubs.acs.org/doi/10.1021/acsbiomaterials.1c00368.

Illustration of making of a cloth mask; SEM images of the fabrics; digital photographs of the fabric samples; plots of average intensity variation at different horizontal locations from the mouth of the subject; frames from the high-speed video for different single-layered face masks, two-layered face masks, and three-layered face masks; digital photographs of qualitative fit testing; illustration of our recommendation on material combinations and layers for designing an effective cloth mask; table of the position of fabrics for two- and three-layered combinations; table of the pressure drops across different layers 
and combinations of the cloth mask and the surgical mask; and mean airflow resistivity of different layers and combinations of the cloth mask (PDF)

High-speed visualization of the method used for inducing a sneeze wearing a face mask (Movie S1) (MP4)

High-speed visualization of the droplet blocking efficiency with the corresponding average intensity for one scenario for each one-layered, two-layered, and three-layered combinations (Movie S2) (MP4)

\section{AUTHOR INFORMATION}

\section{Corresponding Author}

Shovon Bhattacharjee - Biosecurity Program, The Kirby Institute, Faculty of Medicine, University of New South Wales, Sydney, NSW 2052, Australia; (1) orcid.org/00000003-1241-641X; Email: shovon.bhattacharjee@ student.unsw.edu.au

\section{Authors}

Prateek Bahl - School of Mechanical \& Manufacturing Engineering, University of New South Wales, Sydney, NSW 2052, Australia; 이이이.org/0000-0002-0978-2286

Charitha de Silva - School of Mechanical \& Manufacturing Engineering, University of New South Wales, Sydney, NSW 2052, Australia

Con Doolan - School of Mechanical \& Manufacturing Engineering, University of New South Wales, Sydney, NSW 2052, Australia

Abrar Ahmad Chughtai - School of Population Health, University of New South Wales, Sydney, NSW 2052, Australia

David Heslop - School of Population Health, University of New South Wales, Sydney, NSW 2052, Australia

Chandini Raina MacIntyre - Biosecurity Program, The Kirby Institute, Faculty of Medicine, University of New South Wales, Sydney, NSW 2052, Australia; College of Public Service and Community Solutions and College of Health Solutions, Arizona State University, Tempe, Arizona 85287, United States

Complete contact information is available at: https://pubs.acs.org/10.1021/acsbiomaterials.1c00368

\section{Author Contributions}

S.B. and P.B. contributed equally. S.B. and P.B. designed the study, performed the experiments, and drafted the manuscript. C.d.S., C.D., A.A.C., D.H., and C.R.M. supervised the study and revised the manuscript.

\section{Notes}

The authors declare no competing financial interest.

\section{ACKNOWLEDGMENTS}

This work was supported by a grant from the NHMRC Centre for Research Excellence, Integrated Systems for Epidemic Response (ISER) (Grant number 1107393). C.R.M. is supported by an NHMRC Principal Research Fellowship (Grant number 1137582). S.B. is supported by a UNSW Scientia Ph.D. scholarship. The authors acknowledge the facilities and the technical assistance of Microscopy Australia at the Electron Microscope Unit (EMU) within the Mark Wainwright Analytical Centre (MWAC) at UNSW Sydney.

\section{REFERENCES}

(1) Li, Q.; Guan, X.; Wu, P.; Wang, X.; Zhou, L.; Tong, Y.; Ren, R.; Leung, K. S. M.; Lau, E. H. Y.; Wong, J. Y.; Xing, X.; Xiang, N.; Wu, Y.; Li, C.; Chen, Q.; Li, D.; Liu, T.; Zhao, J.; Liu, M.; Tu, W.; Chen, C.; Jin, L.; Yang, R.; Wang, Q.; Zhou, S.; Wang, R.; Liu, H.; Luo, Y.; Liu, Y.; Shao, G.; Li, H.; Tao, Z.; Yang, Y.; Deng, Z.; Liu, B.; Ma, Z.; Zhang, Y.; Shi, G.; Lam, T. T. Y.; Wu, J. T.; Gao, G. F.; Cowling, B. J.; Yang, B.; Leung, G. M.; Feng, Z. Early Transmission Dynamics in Wuhan, China, of Novel Coronavirus-Infected Pneumonia. N. Engl. J. Med. 2020, 382, 1199-1207.

(2) Chan, J. F.-W.; Yuan, S.; Kok, K.-H.; To, K. K.-W.; Chu, H.; Yang, J.; Xing, F.; Liu, J.; Yip, C. C.-Y.; Poon, R. W.-S.; Tsoi, H.-W.; Lo, S. K.-F.; Chan, K.-H.; Poon, V. K.-M.; Chan, W.-M.; Ip, J. D.; Cai, J.-P.; Cheng, V. C.-C.; Chen, H.; Hui, C. K.-M.; Yuen, K.-Y. A familial cluster of pneumonia associated with the 2019 novel coronavirus indicating person-to-person transmission: a study of a family cluster. Lancet 2020, 395, 514-523.

(3) Morawska, L.; Cao, J. Airborne transmission of SARS-CoV-2: The world should face the reality. Environ. Int. 2020, 139, No. 105730.

(4) Zhang, R.; Li, Y.; Zhang, A. L.; Wang, Y.; Molina, M. J. Identifying airborne transmission as the dominant route for the spread of COVID-19. Proc. Natl. Acad. Sci. U.S.A. 2020, 117, 14857.

(5) Bahl, P.; de Silva, C.; Bhattacharjee, S.; Stone, H.; Doolan, C.; Chughtai, A. A.; MacIntyre, C. R. Droplets and Aerosols Generated by Singing and the Risk of Coronavirus Disease 2019 for Choirs. Clin. Infect. Dis. 2020, No. ciaa1241.

(6) Bourouiba, L. Turbulent Gas Clouds and Respiratory Pathogen Emissions: Potential Implications for Reducing Transmission of COVID-19. JAMA 2020, 323, 1837-1838.

(7) Bahl, P.; Doolan, C.; de Silva, C.; Chughtai, A. A.; Bourouiba, L.; MacIntyre, C. R. Airborne or Droplet Precautions for Health Workers Treating Coronavirus Disease 2019? J. Infect. Dis. 2020, No. jiaa189.

(8) MacIntyre, C. R.; Wang, Q. Physical distancing, face masks, and eye protection for prevention of COVID-19. Lancet 2020, 395, 19501951.

(9) WHO. Advice on the Use of Masks in the Context of COVID19. https://www.who.int/publications/i/item/advice-on-the-use-ofmasks-in-the-community-during-home-care-and-in-healthcaresettings-in-the-context-of-the-novel-coronavirus-(2019-ncov)outbreak (accessed June 09, 2020).

(10) Chu, D. K.; Akl, E. A.; Duda, S.; Solo, K.; Yaacoub, S.; Schünemann, H. J.; Chu, D. K.; Akl, E. A.; El-harakeh, A.; Bognanni, A.; Lotfi, T.; Loeb, M.; Hajizadeh, A.; Bak, A.; Izcovich, A.; CuelloGarcia, C. A.; Chen, C.; Harris, D. J.; Borowiack, E.; Chamseddine, F.; Schünemann, F.; Morgano, G. P.; Muti Schünemann, G. E. U.; Chen, G.; Zhao, H.; Neumann, I.; Chan, J.; Khabsa, J.; Hneiny, L.; Harrison, L.; Smith, M.; Rizk, N.; Giorgi Rossi, P.; AbiHanna, P.; El-khoury, R.; Stalteri, R.; Baldeh, T.; Piggott, T.; Zhang, Y.; Saad, Z.; Khamis, A.; Reinap, M.; Duda, S.; Solo, K.; Yaacoub, S.; Schünemann, H. J. Physical distancing, face masks, and eye protection to prevent personto-person transmission of SARS-CoV-2 and COVID-19: a systematic review and meta-analysis. Lancet 2020, 395, 1973-1987.

(11) MacIntyre, C. R.; Chughtai, A. A. Facemasks for the prevention of infection in healthcare and community settings. Br. Med. J. 2015, 350, No. h694.

(12) Bahl, P.; Bhattacharjee, S.; de Silva, C.; Chughtai, A. A.; Doolan, C.; MacIntyre, C. R. Face coverings and mask to minimise droplet dispersion and aerosolisation: a video case study. Thorax 2020, 75, 1024-1025.

(13) Bhattacharjee, S.; Joshi, R.; Chughtai, A. A.; MacIntyre, C. R. Graphene Modified Multifunctional Personal Protective Clothing. Adv. Mater. Interfaces 2019, 6, No. 1900622.

(14) Zangmeister, C. D.; Radney, J. G.; Vicenzi, E. P.; Weaver, J. L. Filtration Efficiencies of Nanoscale Aerosol by Cloth Mask Materials Used to Slow the Spread of SARS-CoV-2. ACS Nano 2020, 14, 91889200. 
(15) CDC. Use of Cloth Face Coverings to Help Slow the Spread of COVID-19. https://www.cdc.gov/coronavirus/2019-ncov/preventgetting-sick/diy-cloth-face-coverings.html (accessed June 03, 2020).

(16) Konda, A.; Prakash, A.; Moss, G. A.; Schmoldt, M.; Grant, G. D.; Guha, S. Aerosol Filtration Efficiency of Common Fabrics Used in Respiratory Cloth Masks. ACS Nano 2020, 14, 6339-6347.

(17) Rodriguez-Palacios, A.; Cominelli, F.; Basson, A. R.; Pizarro, T. T.; Ilic, S. Textile Masks and Surface Covers-A Spray Simulation Method and a "Universal Droplet Reduction Model" Against Respiratory Pandemics. Front. Med. 2020, 7, No. 260.

(18) Zhao, M.; Liao, L.; Xiao, W.; Yu, X.; Wang, H.; Wang, Q.; Lin, Y. L.; Kilinc-Balci, F. S.; Price, A.; Chu, L.; Chu, M. C.; Chu, S.; Cui, Y. Household Materials Selection for Homemade Cloth Face Coverings and Their Filtration Efficiency Enhancement with Triboelectric Charging. Nano Lett. 2020, 20, 5544-5552.

(19) Mueller, A. V.; Eden, M. J.; Oakes, J. M.; Bellini, C.; Fernandez, L. A. Quantitative Method for Comparative Assessment of Particle Removal Efficiency of Fabric Masks as Alternatives to Standard Surgical Masks for PPE. Matter 2020, 3, 950-962.

(20) Aydin, O.; Emon, B.; Cheng, S.; Hong, L.; Chamorro, L. P.; Saif, M. T. A. Performance of fabrics for home-made masks against the spread of COVID-19 through droplets: A quantitative mechanistic study. Extreme Mech. Lett. 2020, 40, No. 100924.

(21) Kähler, C. J.; Hain, R. Fundamental protective mechanisms of face masks against droplet infections. J. Aerosol Sci. 2020, 148, No. 105617.

(22) van der Sande, M.; Teunis, P.; Sabel, R. Professional and Home-Made Face Masks Reduce Exposure to Respiratory Infections among the General Population. PLoS One 2008, 3, No. e2618.

(23) Shakya, K. M.; Noyes, A.; Kallin, R.; Peltier, R. E. Evaluating the efficacy of cloth facemasks in reducing particulate matter exposure. J. Exposure Sci. Environ. Epidemiol. 2017, 27, 352-357.

(24) Davies, A.; Thompson, K.-A.; Giri, K.; Kafatos, G.; Walker, J.; Bennett, A. Testing the Efficacy of Homemade Masks: Would They Protect in an Influenza Pandemic? Disaster Med. Public Health Preparedness 2013, 7, 413-418.

(25) Rengasamy, S.; Eimer, B.; Shaffer, R. E. Simple respiratory protection - Evaluation of the filtration performance of cloth masks and common fabric materials against $20-1000 \mathrm{~nm}$ size particles. Ann. Occup. Hyg. 2010, 54, 789-798.

(26) Fischer, E. P.; Fischer, M. C.; Grass, D.; Henrion, I.; Warren, W. S.; Westman, E. Low-cost measurement of face mask efficacy for filtering expelled droplets during speech. Sci. Adv. 2020, 6, No. eabd 3083.

(27) Asadi, S.; Cappa, C. D.; Barreda, S.; Wexler, A. S.; Bouvier, N. M.; Ristenpart, W. D. Efficacy of masks and face coverings in controlling outward aerosol particle emission from expiratory activities. Sci. Rep. 2020, 10, No. 15665.

(28) Verma, S.; Dhanak, M.; Frankenfield, J. Visualizing the effectiveness of face masks in obstructing respiratory jets. Phys. Fluids 2020, 32, No. 061708.

(29) Verma, S.; Dhanak, M.; Frankenfield, J. Visualizing droplet dispersal for face shields and masks with exhalation valves. Phys. Fluids 2020, 32, No. 091701.

(30) Xiao, L. I.; Sakagami, H.; Miwa, N. A New Method for Testing Filtration Efficiency of Mask Materials Under Sneeze-like Pressure. In Vivo 2020, 34, 1637.

(31) O’Kelly, E.; Pirog, S.; Ward, J.; Clarkson, P. J. Ability of fabric face mask materials to filter ultrafine particles at coughing velocity. BMJ Open 2020, 10, No. e039424.

(32) Bahl, P.; de Silva, C. M.; Chughtai, A. A.; MacIntyre, C. R.; Doolan, C. An experimental framework to capture the flow dynamics of droplets expelled by a sneeze. Exp. Fluids 2020, 61, No. 176.

(33) Duguid, J. P. The size and the duration of air-carriage of respiratory droplets and droplet-nuclei. Epidemiol. Infect. 1946, 44, 471-479.

(34) MATLAB Image Processing Toolbox (R2019a); The MathWorks Inc.: Natick, 2019.
(35) Morawska, L. Droplet fate in indoor environments, or can we prevent the spread of infection? Indoor Air 2006, 16, 335-347.

(36) Bhattacharjee, S.; Bahl, P.; Chughtai, A. A.; MacIntyre, C. R. Last-resort strategies during mask shortages: optimal design features of cloth masks and decontamination of disposable masks during the COVID-19 pandemic. BMJ Open Respir. Res. 2020, 7, No. e000698.

(37) Mates, J. E.; Schutzius, T. M.; Bayer, I. S.; Qin, J.; Waldroup, D. E.; Megaridis, C. M. Water-Based Superhydrophobic Coatings for Nonwoven and Cellulosic Substrates. Ind. Eng. Chem. Res. 2014, 53, 222-227.

(38) Bhattacharjee, S.; MacIntyre, C. R.; Wen, X.; Bahl, P.; Kumar, U.; Chughtai, A. A.; Joshi, R. Nanoparticles incorporated graphenebased durable cotton fabrics. Carbon 2020, 166, 148-163.

(39) Akin, D. Linen Most Useful: Perspectives on Structure, Chemistry, and Enzymes for Retting Flax. ISRN Biotechnol. 2013, 2013, No. 186534.

(40) Bhattacharjee, S.; MacIntyre, C. R.; Bahl, P.; Kumar, U.; Wen, X.; Aguey-Zinsou, K.-F.; Chughtai, A. A.; Joshi, R. Reduced Graphene Oxide and Nanoparticles Incorporated Durable Electroconductive Silk Fabrics. Adv. Mater. Interfaces 2020, 7, No. 2000814.

(41) Zaman, M.; Liu, H.; Xiao, H.; Chibante, F.; Ni, Y. Hydrophilic modification of polyester fabric by applying nanocrystalline cellulose containing surface finish. Carbohydr. Polym. 2013, 91, 560-567.

(42) Mikhailova, O. V.; Pavlov, N. N.; Barantsev, V. M.; Degtyarev, S. V. Increasing the hydrophilicity of polyester fibres and fabrics by treatment with solutions of metal salts. Fibre Chem. 2008, 40, 107109.

(43) Emi, H.; Okuyama, K.; Yoshioka, N. Prediction of collection efficiency of aerosols by high-porosity fibrous filter. J. Chem. Eng. Jpn. 1973, 6, 349-354.

(44) Lee, K. W.; Liu, B. Y. H. Theoretical Study of Aerosol Filtration by Fibrous Filters. Aerosol Sci. Technol. 1982, 1, 147-161.

(45) Hinds, W. C. Aerosol Technology: Properties, Behavior, and Measurement of Airborne Particles, 2nd ed.; Wiley: New York, 1999.

(46) Mainelis, G.; Willeke, K.; Baron, P.; Grinshpun, S. A.; Reponen, T. Induction Charging and Electrostatic Classification of MicrometerSize Particles for Investigating the Electrobiological Properties of Airborne Microorganisms. Aerosol Sci. Technol. 2002, 36, 479-491.

(47) MacIntyre, C. R.; Dung, T. C.; Chughtai, A. A.; Seale, H.; Rahman, B. Contamination and washing of cloth masks and risk of infection among hospital health workers in Vietnam: a post hoc analysis of a randomised controlled trial. BMJ Open 2020, 10 (9), e042045. 